Article

\title{
In-Situ Epoxidation of Waste Cooking Oil and Its Methyl Esters for Lubricant Applications: Characterization and Rheology
}

\author{
Atanu Kumar Paul ${ }^{1}$ (D), Venu Babu Borugadda ${ }^{2}$ and Vaibhav V. Goud ${ }^{1, *(D)}$ \\ 1 Department of Chemical Engineering, Indian Institute of Technology Guwahati, Guwahati 781039, India; \\ atanu.2013@iitg.ac.in \\ 2 Department of Chemical and Biological Engineering, University of Saskatchewan, Saskatoon, Saskatchewan, \\ SK S7N 5A9, Canada; vbb123@mail.usask.ca \\ * Correspondence: vvgoud@iitg.ac.in; Tel.: +91-361-2582272; Fax: +91-361-2582291
}

Citation: Paul, A.K.; Borugadda,

V.B.; Goud, V.V. In-Situ Epoxidation of Waste Cooking Oil and Its Methyl Esters for Lubricant Applications: Characterization and Rheology. Lubricants 2021, 9, 27. https:// doi.org/10.3390/lubricants9030027

Academic Editor: Buyung Kosasih

Received: 20 January 2021

Accepted: 25 February 2021

Published: 2 March 2021

Publisher's Note: MDPI stays neutral with regard to jurisdictional claims in published maps and institutional affiliations.

Copyright: (C) 2021 by the authors. Licensee MDPI, Basel, Switzerland. This article is an open access article distributed under the terms and conditions of the Creative Commons Attribution (CC BY) license (https:// creativecommons.org/licenses/by/ $4.0 /)$.

\begin{abstract}
In the present investigation, in-situ epoxidation of waste cooking oil and its methyl esters was prepared, and the rheological behavior was analyzed for biolubricant applications. Rheological properties of the prepared epoxides were measured at a temperature of $25-100{ }^{\circ} \mathrm{C}$, at a shear rate ranging from 5 to $300 \mathrm{~s}^{-1}$. As viscosity is one of the critical parameters for potential biolubricant applications, in the present study, the power-law model was used to investigate the flow behavior of the epoxides. The viscosity of epoxidized waste cooking oil and its methyl ester epoxides showed Newtonian flow behavior in the studied temperature range. Different shear rates (5-100, 5-300, $100-300 \mathrm{~s}^{-1}$ ) were studied to determine the shear rate dependency of the epoxidized waste cooking oil and its methyl ester epoxides at different temperatures. From the average viscosity values, it was shown that the epoxides show identical results at all shear rates. The dynamic viscosities of the epoxidized waste cooking oil and its methyl ester epoxides were found to be dependent on fatty acid chain length, unsaturation, and temperature. Detailed physicochemical characterization for epoxide waste cooking oil (EWCO) and epoxide waste cooking oil methyl esters (EWCOME) were carried out to evaluate the properties for suitable biolubricant applications using standard American Society for Testing and Materials (ASTM) and American Oil Chemists' Society (AOCS) methods. Based on the viscosity for EWCO $\left(278.9 \mathrm{~mm}^{2} / \mathrm{s}\right)$ and EWCOME $\left(12.15 \mathrm{~mm}^{2} / \mathrm{s}\right)$ and viscosity index for EWCO (164.94) and EWCOME (151.97) of the prepared epoxides, they could complement the standard ISO vegetable grade (VG) lubricants in the market.
\end{abstract}

Keywords: rheology; waste cooking oil; epoxide; physicochemical properties; viscosity

\section{Introduction}

In recent years, eco-friendly products such as biolubricants have played an important role over conventional products. Renewable feedstocks are bound to gradually complement sources of fossil origin (oil, gas, and coal), both as fuel and as raw materials for the chemical industry [1]. Over the 20th century, great efforts were made by the chemical industry to replace petroleum-based feedstock with renewable resources to reduce the environmental impact $[2,3]$. Among the several renewable sources, non-edible oils and edible waste oils have gained much attention owing to their potential to produce several valueadded domestic and industrial-grade products. Chemical modification of double bonds (unsaturation) offers an appropriate method for producing commercial value-added fuels, chemicals, and lubricants from renewable raw materials [4]. Figure 1 shows the molecular structure of a typical triglyceride molecule for structural modification via epoxidation to prepare biolubricant base stocks. 


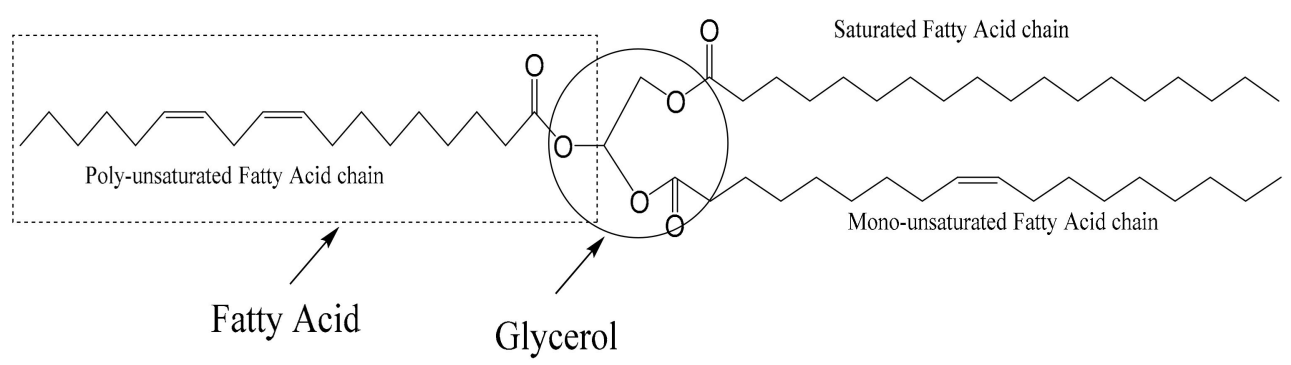

Figure 1. Molecular structure of a typical triglyceride molecule, three fatty acids (saturated, monounsaturated, and polyunsaturated) are connected to glycerol as a backbone.

Besides biodegradability and strong lubricity, vegetable oils are known as a source of renewable energy for future generations. However, high pour point, low oxidative stability, and restricted viscosity range are some of the challenges of vegetable oil derivatives for commercial and domestic applications [5].

The primary function of lubricants is to reduce the wear and friction between the mating surfaces. They also act as coolants and sealants and can avoid corrosion. It was reported that annually 10-15 million tons of fossil-based oleochemicals enter the biosphere [6]. Currently, the Indian lubricant industry is the seventh-largest lubricant market in the world and the sixth-largest automotive lubricant market, and its market is growing $7 \%$ annually [7]. The Indian industrial lubricant market stood at $\$ 1.28$ billion USD in 2017 and is projected to grow to $\$ 1.67$ billion USD by 2023, on the back of strong growth in the construction and mining sectors across the country [8].

Among the several structural modification techniques (such as hydrogenation and epoxidation), epoxidation has found favor as it can produce derivatives with hydroxyl and epoxy functionalities. Epoxidation of the unsaturated bonds occurs along the fatty acid chains to produce a more reactive oxirane group. This three-member ring provides a more energetically favorable site for reaction and represents a chemical intermediate for the preparation of derivatives that would be difficult to obtain directly from the unsaturated bonds [9-11]. Oxirane value is a significant parameter in maintaining epoxide structural integrity. The mechanism involved in the formation of an oxirane ring is shown in Figure 2.

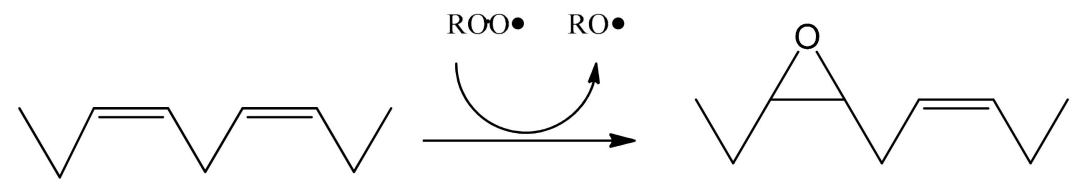

Figure 2. Mechanism involved in the formation of an oxirane ring.

Epoxidized oil is an epoxidized derivative of a mixture of esters of glycerol with various saturated and unsaturated fatty acids. The viscosity of the unmodified oils decreases as the level of oil unsaturation increases. However, the viscosity of the epoxidized oils increases slightly as the level of epoxidation increases. Rheological properties of the epoxides were evaluated by analyzing the effects of epoxidation degree and the epoxide chemical structure. Unmodified plant oils (i.e., soybean, sunflower, passion fruit, moringa, rapeseed, coconut) have low viscosity $\left(\sim 50 \mathrm{~mm}^{2} / \mathrm{s}\right)$ and Newtonian fluids at $40{ }^{\circ} \mathrm{C}$. However, when unmodified oils are chemically modified via epoxidation, hydrogenation, esterification, and transesterification, their viscosity can be increased dramatically, making them suitable for domestic and industrial applications [12]. Further, viscosity depends on the operating temperature; with an increase in temperature, viscosity is reduced. Triglycerides may be changed to provide various functional classes at different functionality levels [13]. As a consequence of chemical modification, the polarities of triglyceride molecules change, which may have a broad influence on rheology [14,15]. 
García-Zapateiro et al. [16] studied thermal and tribological characterization of a variety of estolides, obtained from both oleic and ricinoleic acids, using different acid catalysts. They found that the lubricants prepared via sulfuric acid catalyst influence friction and wear. Campanella et al. [17] reported on the production of polyols with branched ether and ester compounds from epoxidized vegetable oils pertaining to temperature climate crops such as soybean, sunflower, and high-oleic sunflower oils for biolubricant applications. Further, Erhan and Perez [18] analyzed physical, chemical, and kinetic data for cottonseed, corn, and safflower oil-derived base stocks. They found promising results in terms of oxirane content, iodine value, peroxide value, and thermal and kinetic data. It was reported that genetically modified high-oleic vegetable oils performed better than unmodified vegetable oils in terms of thermal and oxidative stability. Likewise, Wang et al. [19] reported that trimethylolpropane fatty acid triester (TFATE) was used as a biolubricant synthesized by transesterification of fatty acid methyl esters from waste cooking oil with trimethylolpropane. In addition, the TFATE's properties met the requirements of ISO vegetable grade (VG) 32. Based on the aforementioned studies on epoxide production and suitable areas of applications, viscosity is one of the most important parameters for a lubricant that controls the thickness of the film. Insufficient lubrication can occur if the viscosity is not within the specified range, resulting in high friction and excessive wear. However, a high viscosity must also be accompanied by a high pressure-viscosity coefficient [20]. Low viscosity can cause oil film failure at high temperatures and high loads, whereas high viscous lubricant can cause excessive heat generation, resulting in oil oxidation, built-up sludge/varnish, and excessive fuel consumption. Suitable viscosity range is therefore very important for different domestic and industrial applications. Viscosity is one of the most critical checks to be performed during automotive engine oil operations. Lubricant oils are graded at different temperatures based on their viscosity. The viscosity depends on the temperature and is reduced as the temperature increases. The viscosity index is an indicator of temperature-viscosity variance. At $100{ }^{\circ} \mathrm{C}$, multigrade engine oils are graded according to their viscosity. For industrial use, the viscosity range is 30 to $240 \mathrm{~mm}^{2} / \mathrm{s}$. Since the viscosity range of vegetable oils/waste oil is very low, to improve the viscosity range, it is important to find acceptable chemical modifications. Limited literature is available on a rheological model fitting waste oil as well as biolubricant base stocks [21-23]. Among the different rheological models like the Andrade equation [24], modified Williams-Landel-Ferry (WLF) equation [23], Arrhenius relationship [25], and Herschel-Bulkley model [26], the power-law model [11,23,25] gained popularity due to its simplicity and fewer assumptions. In this study, epoxidized waste cooking oil and its methyl ester rheological properties were evaluated by varying the temperature and shear rate to determine their rheological behavior. Further, the power-law model was used to fit the outcomes of rheological studies. In conclusion, epoxidized waste cooking oil and its methyl ester viscosity and viscosity index properties were compared with the standard lubricants (vegetable grade) to identify the proper area of application. To our knowledge this the first report on the rheological study of epoxide waste cooking oil (EWCO) and epoxide waste cooking oil methyl esters (EWCOME) for lubricant applications.

\section{Materials and Experimental Methods}

Waste soybean cooking oil was collected from a hostel mess, IIT Guwahati, India. Hydrogen peroxide $\left(\mathrm{H}_{2} \mathrm{O}_{2}, 30 \% v / v\right)$ and sulfuric acid $\left(\mathrm{H}_{2} \mathrm{SO}_{4}, 98 \% v / v\right)$ were purchased from Rankem, and glacial acetic acid $\left(\mathrm{CH}_{3} \mathrm{COOH}, 99-100 \%\right)$ was supplied by Merck India Ltd. All the other reagents were analytical grade and were used as received.

\subsection{Waste Cooking Oil Methyl Esters and Epoxide Synthesis}

Waste cooking oil (WCO) was transesterified via the method reported by Borugadda et al. [27]. Transesterification was carried out in a $500 \mathrm{~mL}$ glass reactor with a condenser on the top for reflux. This reaction setup was kept in a temperature-controlled oil bath, and the transesterification was carried out using a base catalyst $(\mathrm{KOH})$ due to low (less 
than 1) free fatty acid value (WCO: 0.73). A single step transesterification procedure was follows using 1:6 oil to alcohol molar ratio and $1 \mathrm{wt} . \% \mathrm{KOH}$ as catalyst. Initially, WCO was charged in the reactor and heated up to the desired reaction temperature $\left(60^{\circ} \mathrm{C}\right)$ in order to cease the loss of methanol from the reaction because beyond this temperature evaporation of methanol was observed. The alkali catalyst $\mathrm{KOH}(1 \mathrm{wt} . \%)$ was dissolved in methanol to form sodium methoxide solution and was prepared freshly in order to avoid moisture absorbance and to maintain the catalytic activity. The prepared sodium methoxide solution was slowly added to the preheated WCO. The system was totally closed to the atmosphere to prevent the loss of alcohol, and stirred for $90 \mathrm{~min}$. After completion of the reaction, the mixture was cooled and transferred into a separating funnel and allowed to settle overnight for separation. The upper layer contained methyl esters, residual methanol, and catalyst, whereas the lower layer contained glycerol and impurities. The glycerol layer was drawn off using the separating funnel, and the methyl ester layer was washed with warm Millipore water $\left(40^{\circ} \mathrm{C}\right)$ until the washing water had the $\mathrm{pH}$ of the Millipore water. Methyl ester was dried at $60{ }^{\circ} \mathrm{C}$ under vacuum by using a rotary evaporator (BUCHI Rotavapor, Model R 200) to remove the water content. The obtained yield of methyl ester was $95 \%$, and the physicochemical properties of the prepared methyl ester were estimated according to the standard American Society for Testing and Materials (ASTM) and American Oil Chemists' Society (AOCS) methods.

WCO epoxidation was also carried out in an identical setup in a $500 \mathrm{~mL}$ capacity baffled flask with a plain bottom. Initially, WCO or WCOME was heated to $60{ }^{\circ} \mathrm{C}$ temperature, then glacial acetic acid was added according to mole calculation, $\mathrm{H}_{2} \mathrm{SO}_{4}$ was added as weight calculation, and finally $\mathrm{H}_{2} \mathrm{O}_{2}$ was added dropwise to the reaction mixture. The amount of $\mathrm{H}_{2} \mathrm{O}_{2}$ was calculated using the molecular weight of the WCO or WCOME. A stirring speed of 1100-1500 rpm was kept to ensure uniform mixing. After the complete addition of $\mathrm{H}_{2} \mathrm{O}_{2}$, the reaction was continued for the desired duration. The experimental conditions were as follows: 2 moles of $\mathrm{H}_{2} \mathrm{O}_{2} ; 1.5 \mathrm{wt}$.\% catalyst loading, and $6 \mathrm{~h}$ reaction time; at this condition the oxirane oxygen content (OOC) of EWCO was found to be 4.7 mass $\%$.

WCOME epoxidation was carried out in the same setup of WCO epoxidation reaction; $25 \mathrm{~g}$ of WCOME $(0.433 \mathrm{~mol})$ was initially heated to the reaction temperature $\left(60^{\circ} \mathrm{C}\right)$, then $3.25 \mathrm{~g}(0.216 \mathrm{~mol})$ of glacial acetic acid and catalyst $(0.382 \mathrm{gm})$ were added. When the temperature was $5{ }^{\circ} \mathrm{C}$ below the reaction temperature, hydrogen peroxide was introduced dropwise to the reaction mixture in the first $30 \mathrm{~min}$ to prevent explosion. A stirring speed of 1000-1500 rpm was maintained to ensure uniform mixing of the reaction mixture. Upon completion of epoxidation, samples were repeatedly washed with warm Millipore water $\left(40{ }^{\circ} \mathrm{C}\right)$ to eliminate the catalyst and other reactants and make it neutral. Finally, the solvent and trace water were distilled off using a rotary evaporator. The oxirane oxygen content and IV of the final epoxide product were calculated.

\subsection{Physical and Chemical Properties of EWCO and EWCOME}

Acid value (AV) and free fatty acid (FFA) content of WCO and its epoxides were determined according to the AOCS official method (Te 1a-64, 1997). Density and specific gravity were measured using a specific gravity bottle. Refractive index (RI) was measured using a refractometer (Abbe refractormeter). Epoxide moisture content was determined using a Karl-Fischer auto-titrator.

\subsection{Rheological Measurements}

Rheology of the epoxides $(\sim 0.6 \mathrm{~mL})$ was performed using an interfacial rheometer (Anton-Paar Model: MCR 301) by varying the temperature from 25 to $100{ }^{\circ} \mathrm{C}$ and shear rate in the range of 5 to $300 \mathrm{~s}^{-1}$. A thermostatic water bath was used to control the working temperature within the set range of 40 to $100 \pm 0.1^{\circ} \mathrm{C}$. A rheometer with two different plates (PP 50-1, diameter: 50 mm; INSET I-PP 80/SS, diameter: $80 \mathrm{~mm}$ ) was used. During the measurement, epoxide temperature was maintained at a constant within $\pm 0.1{ }^{\circ} \mathrm{C}$ 
variations. The measurements were triplicated, and the average values are reported. The maximum uncertainties of viscosity determinations were found to be less than $\pm 3 \%$.

\subsection{Iodine Value ( $\left.I V, g I_{2} / 100 g\right)$}

The iodine value can be defined as the "mass of iodine in grams consumed by $100 \mathrm{~g}$ of oil". It determines the amount of unsaturation (double bonds) contained in waste cooking oil, its methyl esters, and their epoxides. The IV greatly influences oxidation and aging and is determined according to Wijs' method (AOCS Tg 1-64, 1997). A higher iodine value signifies more unsaturation in the epoxide. The epoxide with a low IV is always preferred for biolubricant applications [26]. Each IV analysis was run in duplicate, and the average values are presented in this study.

\subsection{Oxirane Value (\% by Mass)}

Oxirane value indicates the mass of oxygen present in the epoxy groups. Oxirane values were experimentally determined with the direct method (AOCS Method Cd-9, 120) II.D.20 (HBr Method) using hydrobromic acid solution in glacial acetic acid [28]. Theoretical oxirane oxygen $\left(O O_{t h}\right)$ and the relative percentage conversion to oxirane was computed from the following expressions:

Theoretical oxirane oxygen content,

$$
\text { OOth }=\left[\frac{(I V o / 2 A i)}{100+(I V o / 2 A i) A o}\right] A 0 \times 100
$$

where $A_{i}$ and $A_{0}$ are the atomic weights of iodine and oxygen, respectively, and $I V_{0}$ is the initial iodine value.

$$
\text { Relative percentage conversion to oxirane }=\left[\frac{\text { OOex }}{\text { OOth }}\right] \times 100
$$

where OOex is the experimentally determined content of oxirane oxygen, and OOth is the theoretically maximum oxirane oxygen content.

\subsection{Chemical Composition (GC)}

The fatty acid composition of the waste cooking oil methyl esters was determined using a Nucon 5765 gas chromatograph equipped with a flame ionization detector (Nucon Engineers, Delhi, India) and fused silica capillary column BPX-70, $60 \mathrm{~m} \times 0.25 \mathrm{~mm} \times$ $0.25 \mu \mathrm{m}$ (SGE, India). The column temperature was programmed to increase from 180 to $240{ }^{\circ} \mathrm{C}$ at $4{ }^{\circ} \mathrm{C} / \mathrm{min}$. The detector and injector temperatures were fixed at 240 and $230{ }^{\circ} \mathrm{C}$, respectively. Nitrogen ( $40 \mathrm{psi}$ ) was used as a carrier gas at a flow rate of $45 \mathrm{~mL} / \mathrm{min}$, while air and hydrogen flow rates were 30 and $300 \mathrm{~mL} / \mathrm{min}$, respectively. The sample injection volume was $1.0 \mu \mathrm{L}$ with a split flow of $60 \mathrm{~mL} / \mathrm{min}$.

\subsection{Differential Scanning Calorimetry (DSC)}

The cold flow behavior of the epoxides was determined by differential scanning calorimetry (201 F1 Phonix, Netzsch, Germany). During the thermal scanning, $10 \mathrm{Mg}$ of epoxides were used under nitrogen purging at $100 \mathrm{~mL} / \mathrm{min}$. DSC measurements were carried out according to the procedure reported in our previous study [25].

\section{Results and Discussion}

\subsection{Physicochemical Properties of WCO and WCOME Epoxides}

Physicochemical properties of the epoxides were determined to ascertain their quality, and Table 1 shows the properties of EWCO and EWCOME. The lower acid value ( 0.3 and 0.2) signifies that EWCO and EWCOME do not create any trouble for or damage (due to corrosion) to the machinery during its usage. Free fatty acid (FFA) content is always half of the $\mathrm{AV}$, which indicates the formation of soap when it is mixed with water; the estimated 
FFA value is considerably lower $(0.15$ and $0.10 \mathrm{Mg} \mathrm{KOH} / \mathrm{g}$, respectively). Similarly, the density of WCO was found to be $760 \mathrm{~kg} / \mathrm{m}^{3}$, and after chemical modification (EWCO) it was increased to $802 \mathrm{~kg} / \mathrm{m}^{3}$. An increase in viscosity is owing to the increased molecular weight, which is attributed to the addition of the oxygen molecule at the unsaturation sites, polarity, and intermolecular forces in the epoxide after reaction [29].

The measurement of IV (i.e., unsaturation sites) after epoxidation is one of the ways to confirm the completion of epoxide formation. Initial IV of WCO was found to be 132.9 ( $\mathrm{g} \mathrm{I}_{2} / 100 \mathrm{~g}$ of oil), whereas after the reaction it was found to be 1.74 ( $\mathrm{g} \mathrm{I}_{2} / 100 \mathrm{~g}$ of epoxide). From the IV it was confirmed that $98.66 \%$ double bonds were transformed into oxirane rings via epoxidation as shown in Figure 3, and the conversion was calculated based on initial and final IVs. These three-membered rings of oxirane could form a smooth layer due to tribopolymerization, which is tribologically effective to reduce friction during usage [30]. Similarly, relative percentage conversion to oxirane was found to be $60.75 \%$ (based on Equation (1)). One of the important properties of epoxide is moisture content, which indicates the presence of water in the epoxide. In general, the presence of moisture encourages the bacteria to grow; this leads to increased AV, viscosity, and free radical compounds via oxidation [31]. In this study, epoxide moisture content was found to be 0.25 and 0.18 wt.\% respectively (Table 1 ), which again favors the usage of EWCO and EWCOME without any trouble. The refractive index of EWCO was found to be 1.47 (Table 1), which shows that a significantly smaller amount of heat energy can pass through the epoxide, which is the desired property for lubricants to maintain their structural integrity. Lower refractive index lubricants are preferred to avoid thermal variations in the application point of view during usage. Lower specific gravity (0.7) of the EWCOME indicated the completion of the reaction and removal of heavy glycerine from the EWCOME.

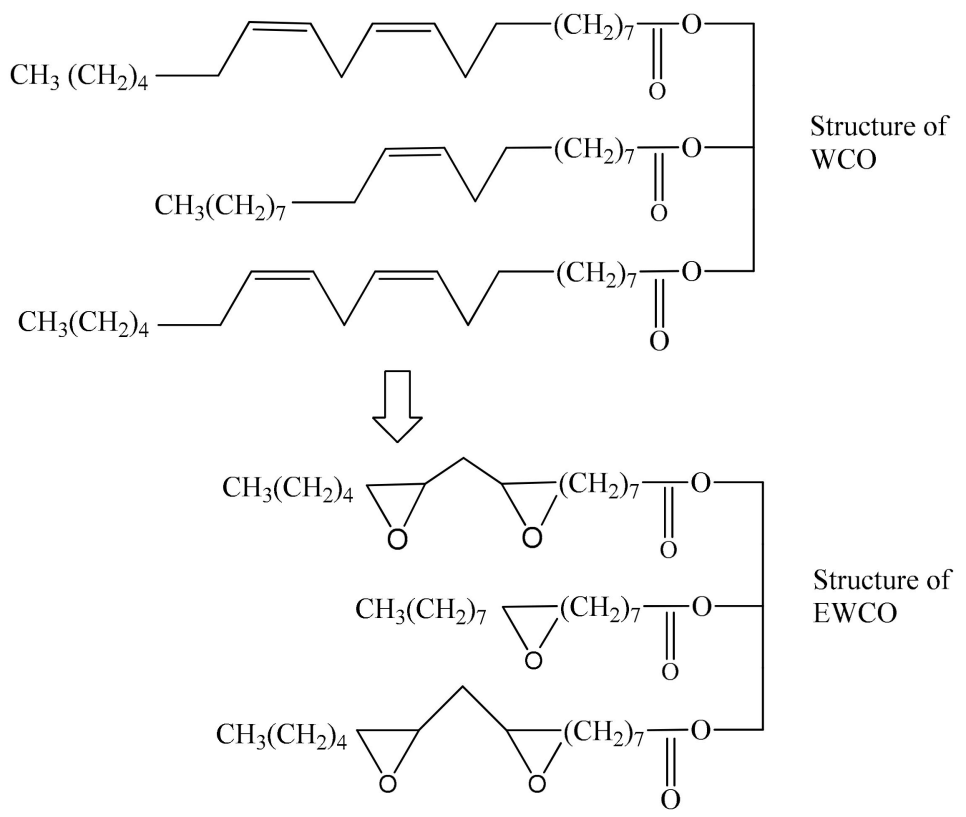

Figure 3. Chemical structure of the fatty acids present in the waste cooking oil (WCO) and epoxide waste cooking oil (EWCO).

The structure of the epoxides derived from natural triglycerides is located along a hydrocarbon chain so that each carbon of the cyclic ether bears an alkyl substituent. To make use of epoxides for a specific application, they should maintain their physical, chemical, and structural integrity at all storage conditions. The epoxidized derivatives can be used as lubricant base fluids due to their good lubricity and higher thermo-oxidative stability compared to their structurally unmodified feedstock [32]. 
Table 1. Comparison of physicochemical properties of EWCO and EWCOME

\begin{tabular}{|c|c|c|c|c|c|c|c|c|}
\hline Properties & Unit & EWCO & EWCOME & WCO & $\begin{array}{c}\text { Epoxidized Waste } \\
\text { Cooking Oil Fatty } \\
\text { Acid Methyl } \\
\text { Esters [12] }\end{array}$ & $\begin{array}{c}\text { Methyl Ester of 9,10- } \\
\text { Palmitoyloxy-Acetoxy } \\
\text { Stearic Acid } \\
\text { (MEPASA) [33] }\end{array}$ & $\begin{array}{c}\text { Epoxidized } \\
\text { Soybean Oil } \\
(\text { ESBO) [34] }\end{array}$ & ISO VG 32 [12] \\
\hline Specific gravity & - & 0.80 & 0.77 & 0.79 & - & - & - & - \\
\hline Kinematic viscosity $^{a}$ & $\mathrm{~mm}^{2} / \mathrm{s}$ & $278.9 \pm 3.56$ & $12.15 \pm 0.87$ & $49.84 \pm 1.39$ & 15.9 & 44.58 & 170.85 & 28.8 \\
\hline Density & $\mathrm{kg} / \mathrm{m}^{3}$ & $802.1 \pm 4.89$ & $773.8 \pm 3.71$ & $792.05 \pm 4.58$ & - & 942 & - & - \\
\hline Iodine value & $\mathrm{g} \mathrm{I}_{2} / 100 \mathrm{~g}$ & $1.74 \pm 0.14$ & $2.41 \pm 0.17$ & $132.94 \pm 2.94$ & - & 5.05 & 9.11 & - \\
\hline Acid value & $\mathrm{Mg} \mathrm{KOH} / \mathrm{g}$ & $0.30 \pm 0.07$ & $0.20 \pm 0.04$ & $3.0 \pm 0.12$ & - & - & 0.09 & - \\
\hline Free fatty acid & $\mathrm{Mg} \mathrm{KOH} / \mathrm{g}$ & $0.15 \pm 0.04$ & $0.10 \pm 0.02$ & $1.5 \pm 0.05$ & - & - & 0.045 & - \\
\hline Refractive index at $24^{\circ} \mathrm{C}$ & - & $1.47 \pm 0.1$ & $1.48 \pm 0.08$ & $1.47 \pm 0.07$ & - & - & - & - \\
\hline Pour point & ${ }^{\circ} \mathrm{C}$ & $-6.2 \pm 0.17$ & $2.40 \pm 0.03$ & $-7.8 \pm 0.13$ & -15 & -20 & - & -6 \\
\hline Moisture content & $\%$ & $0.25 \pm 0.02$ & $0.18 \pm 0.03$ & $0.27 \pm 0.02$ & - & - & - & - \\
\hline Oxirane content (experimental) & - & $4.69 \pm 0.4$ & $4.81 \pm 0.5$ & - & - & - & - & - \\
\hline Oxirane content (theoretical) & - & $7.72 \pm 0.2$ & $7.94 \pm 0.3$ & - & - & - & - & - \\
\hline $\begin{array}{c}\text { Relative percentage Conversion of } \\
\text { oxirane }(\%)\end{array}$ & - & 60.75 & 60.57 & - & - & - & - & - \\
\hline
\end{tabular}


Further fatty acid composition of WCO methyl esters was analyzed, and the saturated fatty acid (FA) content was found to be $18.27 \mathrm{wt} . \%$. The rest of the fatty acids were unsaturated, which led to lower thermal stability (Table 2).

Table 2. Fatty acid composition of the oils.

\begin{tabular}{cccc}
\hline Fatty Acid & Carbon Number & Fatty Acid Composition (\%) of WCO, WCOME & The Chemical Name of the Fatty Acid \\
\hline Oleic & $(\mathrm{C} 18: 1)$ & $23.96 \pm 1.6$ & 9-octadecenoic \\
Linoleic & $(\mathrm{C} 18: 2)$ & $39.16 \pm 1.7$ & 9,12 -octadecadienoic \\
Linolenic & $(\mathrm{C} 18: 3)$ & $5.25 \pm 0.6$ & $9,12,15$-octadecadienoic \\
Saturated & $(\mathrm{C} 16: 0)$ & $18.27 \pm 1.2$ & - \\
\hline
\end{tabular}

\subsection{Power-Law Model Fitting}

Internal flow property is important for epoxides as potential lubricant base stocks that depend on the fatty acid composition of the WCO. It is one of the significant properties that should be considered for a lubricant's practical application as a base stock. The viscosity of the epoxidized WCO and WCOME exerts a great influence on lubricant dynamic properties, such as circulation and injection during engine operation. Three different regions of shear rates i.e., 5-100, 5-300, and 100-300 $\mathrm{s}^{-1}$, were studied as they exhibit different flow behaviors at these intervals. The plot of shear stress versus the shear rate at 25, 40, 60,80 , and $100{ }^{\circ} \mathrm{C}$ showed a linear relationship with $\mathrm{R}^{2}$ greater than 0.99 (Figure $4 \mathrm{a}, \mathrm{b}$ ). Furthermore, the flow behaviors of the epoxides were analyzed using the power-law model (Equation (3)).

$$
\tau=k \gamma^{n}
$$

where $\tau$ is shear stress $(\mathrm{Pa}), \gamma$ is the shear rate $\left(\mathrm{s}^{-1}\right)$, and $n$ and $k$ are the power-law coefficients, and they can represent the resistance of the fluid to flow. $\mathrm{k}$ is the flow consistency index (Pa. s), and $n$ is the non-Newtonian flow behavior index (dimensionless). $n$ and $k$ values were estimated from the linearization of the power-law equation. The parameters $k$ and $n$ characterize the rheology of power-law fluids. The flow behavior index $n$ is dimensionless; the dimensions of $k$ and $\mathrm{L}^{-1} \mathrm{MT}^{\mathrm{n}-2}$ depend on $n$. For pseudoplastic fluids $n<1$, when $n>1$, the fluid is dilatant rather than pseudoplastic. Dilatant is a recognized category of non-Newtonian fluid behavior; however, dilatant fluids do not occur often in bioprocessing. If $n=1$, the fluid is Newtonian, and as the fluid becomes more viscous, the consistency factor $(k)$ increases; as the fluid shear thinning increases, " $n$ " decreases. If " $n$ " is greater than 1, the fluid is classed as dilatant (the apparent viscosity increases as the shear rate increases). If " $n$ " is between zero and 1 , the fluid is classified as pseudoplastic, exhibiting shear-thinning; (i.e., the apparent viscosity decreases as the shear rate increases).

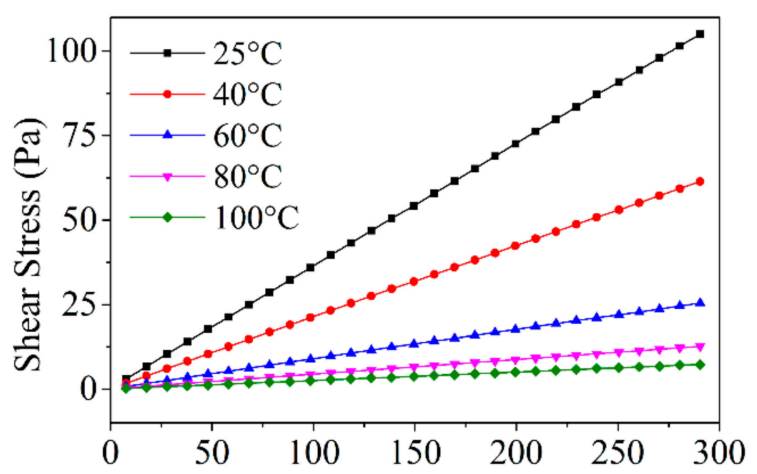

(a)

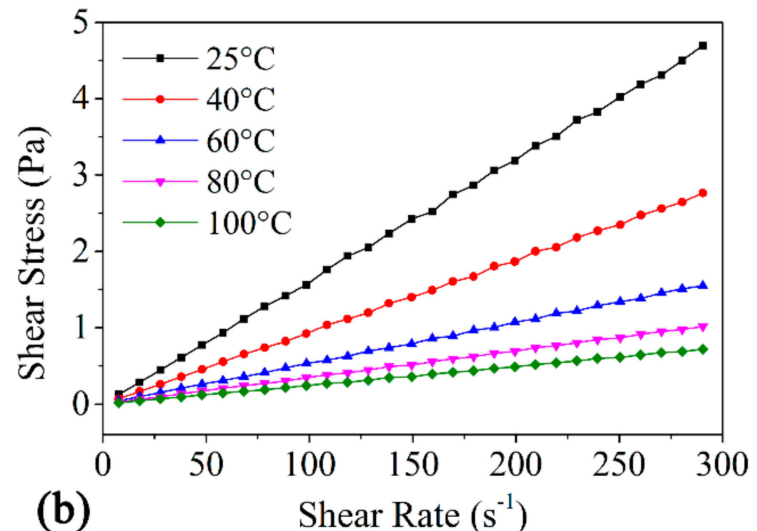

(b)
Shear Rate $\left(\mathrm{s}^{-1}\right)$

Figure 4. Shear stress versus shear rate plot for (a) EWCO, (b) EWCOME. 
The plot of $\ln \gamma$ vs. $\ln \tau$ should be a straight line with slope $n$ and intercept, $\ln k$ (Equation (4)).

$$
\ln \tau=\ln k+n \ln \gamma
$$

Equation (4) is used widely as an engineering calculation because of the simple approximation. The flow behavior index $(n)$ is determined as the gradient of a plot of $\tau$ versus $\gamma$ on logarithmic coordinates. In the case of $n$ being less than unity, it is called a pseudoplastic fluid. This type of behavior is widely encountered in polymer solutions and fine solid particle suspensions. According to Equation (4), a plot between $\ln \tau$ and $\ln \gamma$ is expected to show a straight line relationship (Figure 5a,b) with slope " $n$ " and intercept $\ln k$. The $\ln \tau$ dependence of $\ln \gamma$ for EWCO and EWCOME at various temperatures, ranging from ambient to $100{ }^{\circ} \mathrm{C}$, is shown in Figure 6a,c indicating that, at different temperatures, a linear relationship exists among $\ln \tau$ and $\ln \gamma$. From this dependency $k$ and $n$ values were evaluated by linear regression analysis, and the results are reported in Table 3.
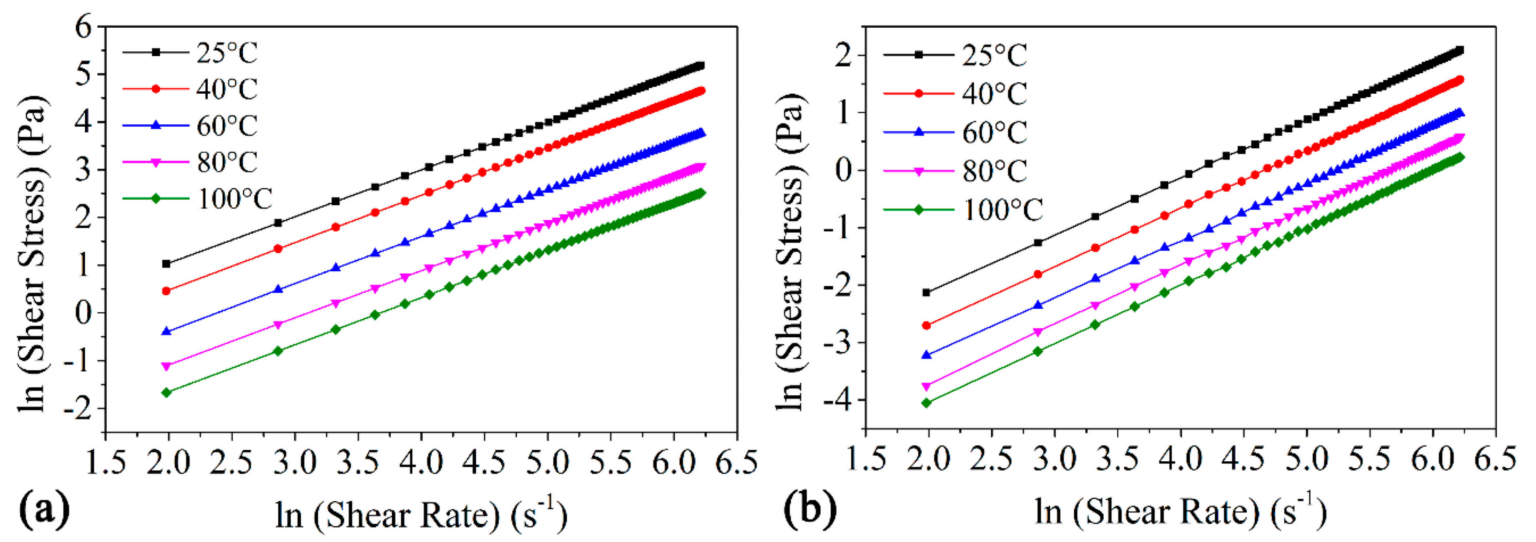

Figure 5. Logarithmic plot of shear stress versus shear rate for (a) EWCO, (b) EWCOME.

The values of flow consistency index obtained from the power-law model $(k)$ and average dynamic viscosity obtained from the experiment $\left(\mathrm{k}_{\exp }\right)$ for the temperature $(40$ and $100{ }^{\circ} \mathrm{C}$ ) are tabulated in Table 3 and shown in Figure $6 \mathrm{a}, \mathrm{c}$. At $40^{\circ} \mathrm{C}$ the $k$ value for EWCO is $212.35 \mathrm{mPa}$.s in full share rate range, and for $100{ }^{\circ} \mathrm{C}$ it is $25.56 \mathrm{mPa}$.s. From this reported value it can be concluded that as temperature increases, EWCO loses its viscous property. The decrease in the consistency index $(k)$ means that the same change in the shear rate causes a lower change in the shear stress [35]. The same trends also followed for EWCOME. As shown in Table 3 the values of flow behavior index $(n)$ of both the samples lie between 0.99-1.00, indicating that EWCO and EWCOME show Newtonian behavior, meaning that viscosity values are not dependent on shear rate. This supports our results, which are shown in Tables 3 and 4 (viscosity values vary approximately within the $5 \%$ range). 

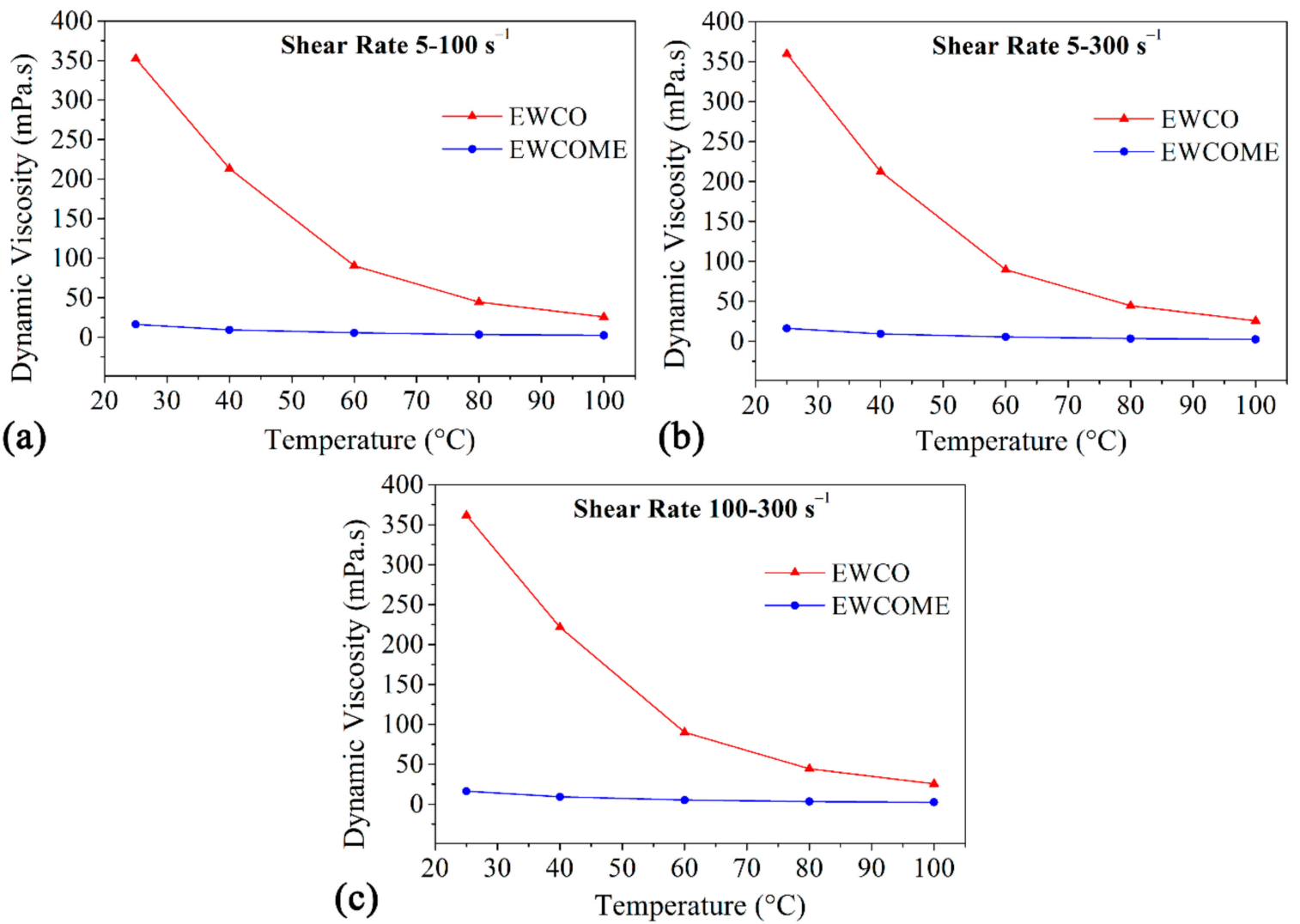

Figure 6. Viscosity versus temperature plot for EWCO and EWCOME at shear rate (a) range 5-100 s ${ }^{-1}$, (b) range 5-300 s ${ }^{-1}$, (c) range $100-300 \mathrm{~s}^{-1}$.

Table 3. $\mathrm{k}, \mathrm{k}_{\text {exp, }}$ and $\mathrm{n}$ values of EWCO and EWCOME at $40{ }^{\circ} \mathrm{C}$.

\begin{tabular}{|c|c|c|c|c|c|c|}
\hline \multirow[b]{2}{*}{ Shear rate $\left(\mathrm{s}^{-1}\right)$} & \multicolumn{3}{|c|}{ EWCO } & \multicolumn{3}{|c|}{ EWCOME } \\
\hline & $5-100$ & $5-300$ & $100-300$ & $5-100$ & $5-300$ & $100-300$ \\
\hline \multicolumn{7}{|c|}{ Temperature $40^{\circ} \mathrm{C}$} \\
\hline $\mathrm{k}$ (mPa.s) & 213.30 & 212.35 & 221.68 & 9.25 & 9.30 & 9.29 \\
\hline $\mathrm{k}_{\exp }(\mathrm{mPa} . \mathrm{s})$ & 222.97 & 224.90 & 239.88 & 9.07 & 9.19 & 9.18 \\
\hline $\mathrm{n}$ & 0.99 & 0.99 & 0.99 & 1.00 & 1.00 & 1.00 \\
\hline \multicolumn{7}{|c|}{ Temperature $100^{\circ} \mathrm{C}$} \\
\hline $\mathrm{k}$ (mPa.s) & 25.56 & 25.56 & 25.53 & 2.42 & 2.40 & 2.40 \\
\hline $\mathrm{k}_{\exp }$ (mPa.s) & 26.72 & 26.38 & 26.24 & 2.41 & 2.39 & 2.39 \\
\hline $\mathrm{n}$ & 0.99 & 0.99 & 0.99 & 1.00 & 1.00 & 1.00 \\
\hline
\end{tabular}

k: flow consistency index obtained from the power-law model, $\mathrm{k}_{\text {exp }}$ : average dynamic viscosity obtained from the experiment, n: non-Newtonian flow behavior index.

A study by Yen and Yang [36] reported similar results on the rheological behavior of polyacrylamide solution. This behavior of epoxide signifies that WCO epoxide adopts Newtonian fluid behavior [37]; therefore, based on the aforementioned rheological characterization, it could be predicted that WCO epoxide provides a smooth performance during its usage without any operational difficulties. The non-Newtonian behavior index (n) versus temperature $\left({ }^{\circ} \mathrm{C}\right)$ plot is shown in Figure $7 \mathrm{a}-\mathrm{c}$, indicating that the $\mathrm{n}$ value was varied from 0.9 to 1 . It was also confirmed that the sample shows Newtonian behavior throughout the temperature variation. The viscosity of the epoxidized oils increased slightly with the extent of epoxidation. The viscosity increased monotonically from approximately $45 \mathrm{mPa}$.s for WCO to as high as $365 \mathrm{mPa}$.s for EWCO with 4.69 mass\% of epoxide groups per triglyceride. At $40{ }^{\circ} \mathrm{C}$, the viscosity of EWCO decreased and showed the value of 
213 mPa.s. Kinematic viscosity for the different temperatures of EWCO and EWCOME is shown in Figure 8.

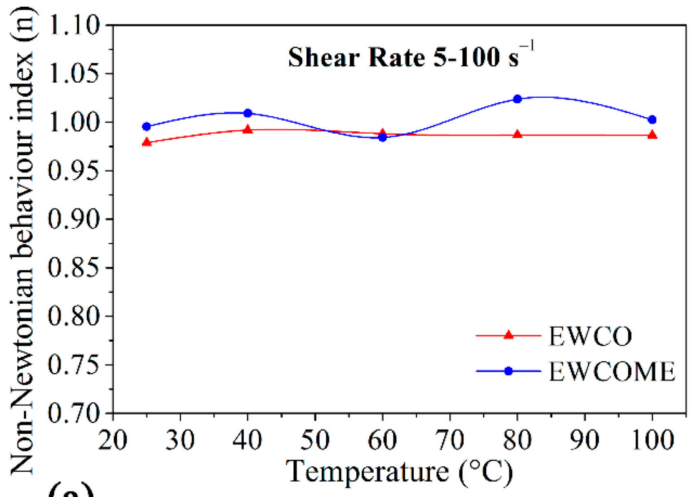

(a)

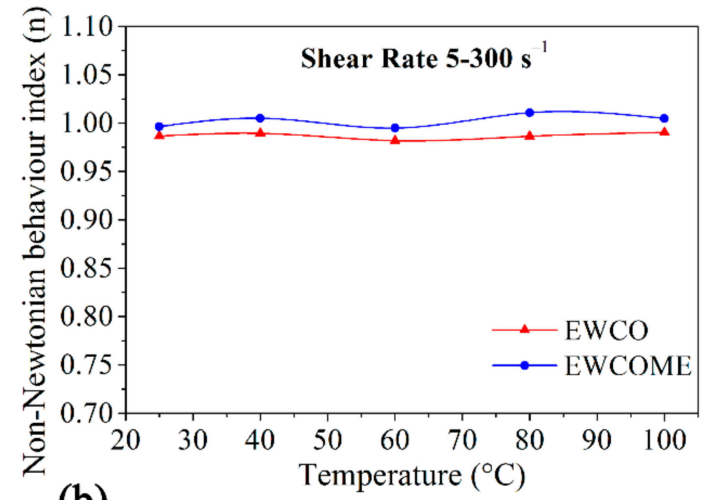

(b)

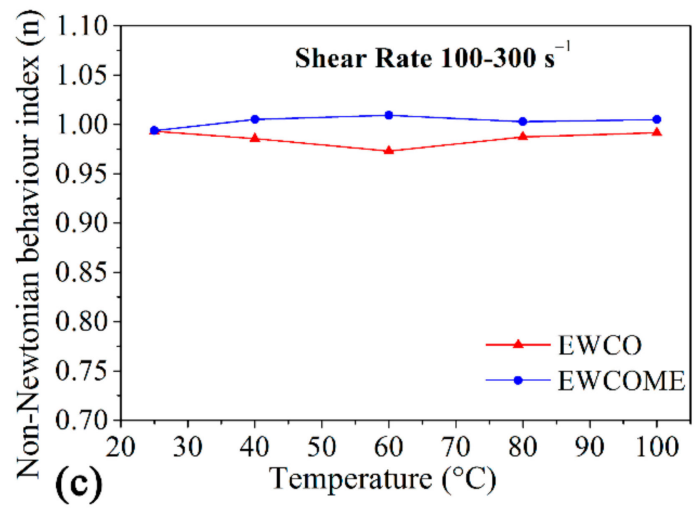

Figure 7. Non-Newtonian flow behavior index plot for EWCO and EWCOME at shear rate (a) range $5-100 \mathrm{~s}^{-1}$, (b) range 5-300 $\mathrm{s}^{-1}$, (c) range 100-300 s $\mathrm{s}^{-1}$.

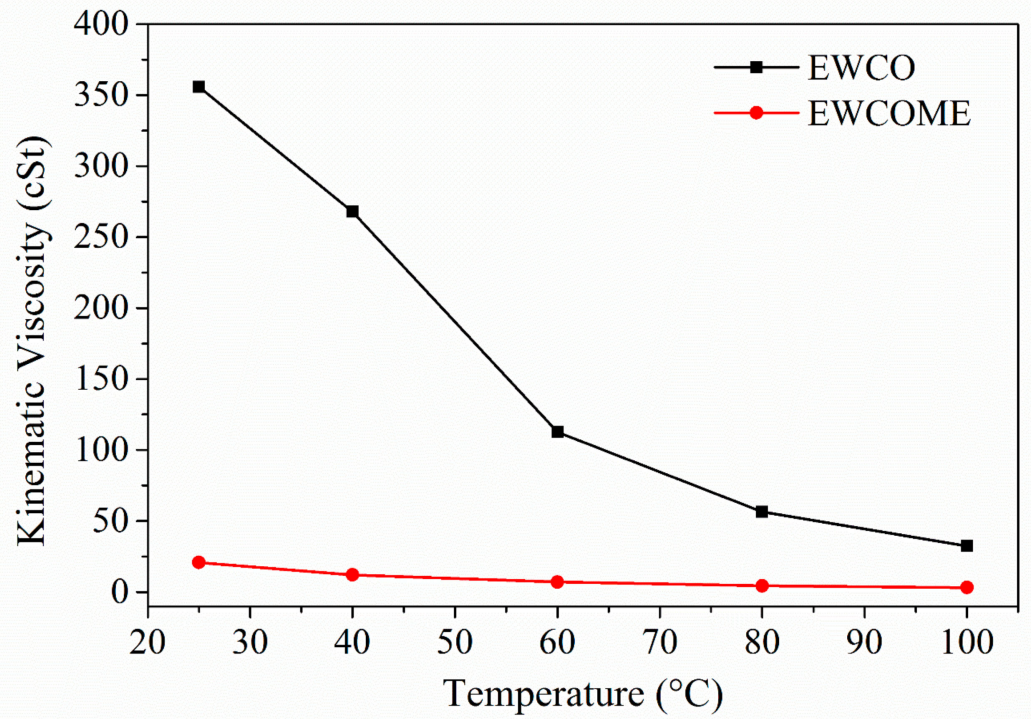

Figure 8. Temperature versus kinematic viscosity plot of EWCO and EWCOME.

\subsection{Applications of EWCO and EWCOME}

Practical applications of the prepared epoxidized waste cooking oil and epoxidized waste cooking oil methyl esters were identified by a relative comparison of the viscosity index with the ISO vegetable grade (VG) lubricants. The viscosity index is one of the critical parameters used to measure the change in viscosity with varying temperatures. 
From Table 4, it can be observed that the epoxidized waste cooking oil and epoxidized waste cooking oil methyl esters could complement up to the ISO VG 220 and ISO VG 10 standards based on the mid-range of the viscosity values relative to the ISO VG standards. Viscosity index (VI) was found to be 164.94 for EWCO and 151.97 for EWCOME, and the VI of both epoxides was found to be in the range of standard lubricant requirements [12]. Hernández-Sierra et al. [20] studied friction and wear for natural oil with synthetic esters; these lubricants showed low friction with a moderate viscosity index. Further, it was observed that high viscosity and a high pressure-viscosity coefficient exhibited the thickest lubricating film. Biolubricants derived from vegetable oils have better lubrication and antiwear capacities relative to other hybrid lubricants (metal-ceramic) in mechanical systems. Those characteristics indicate that the prepared lubricants do not have any technical deficiencies for engineering applications, and that makes vegetable oil derived lubricants a good choice for the manufacture of green lubricants. If high-viscosity lubricating oils are desired, the prepared lubricants can be tailored by blending with additives to boost viscosity for engine, automotive, and industrial gear applications [16]. These VI values are in line with other plant/vegetable oil derived biolubricants, like epoxidized fatty acid waste cooking oil methyl esters (157) [12], ring opened epoxidized soybean oil (137149) [38], methyl ester of 9,10-palmitoyloxy-acetoxy stearic acid (171), and methyl ester of 9,10-lauroyloxy-capronoyloxy stearic acid (137) [33].

Table 4. Relative comparison of the viscosity for the prepared biolubricants with ISO vegetable grade (VG) lubricants.

\begin{tabular}{|c|c|c|c|c|}
\hline \multirow{2}{*}{ ISO Viscosity } & \multirow{2}{*}{$\begin{array}{c}\text { Viscosity at } 40{ }^{\circ} \mathrm{C}\left(\mathrm{mm}^{2} / \mathrm{s}\right) \\
\text { Mid-Range }\end{array}$} & \multicolumn{2}{|c|}{ Viscosity Limits $\left(\mathrm{mm}^{2} / \mathrm{s}\right)$} & \multirow[b]{2}{*}{ Viscosity Index [12] } \\
\hline & & Minimum & Maximum & \\
\hline $\begin{array}{l}\text { Epoxidized waste cooking oil } \\
\text { (present study) }\end{array}$ & 267.92 & 248.65 & 281.45 & 164.94 \\
\hline $\begin{array}{l}\text { Epoxidized waste cooking oil methyl esters } \\
\text { (present study) }\end{array}$ & 12.15 & 10.47 & 13.84 & 151.97 \\
\hline ISO VG 2 & 2.2 & 1.98 & 2.42 & - \\
\hline ISO VG 3 & 3.2 & 2.88 & 3.52 & - \\
\hline ISO VG 5 & 4.6 & 4.14 & 4.06 & - \\
\hline ISO VG 7 & 6.8 & 6.12 & 7.48 & - \\
\hline ISO VG 10 & 10 & 9.00 & 11 & - \\
\hline ISO VG 15 & 15 & 13.50 & 16.5 & - \\
\hline ISO VG 22 & 22 & 19.80 & 24.2 & - \\
\hline ISO VG 32 & 32 & 28.80 & 35.2 & $>90$ \\
\hline ISO VG 46 & 46 & 41.40 & 50.6 & $>90$ \\
\hline ISO VG 68 & 68 & 61.20 & 74.8 & $>198$ \\
\hline ISO VG 100 & 100 & 90 & 110 & $>216$ \\
\hline ISO VG 150 & 150 & 135 & 165 & - \\
\hline ISO VG 220 & 220 & 198 & 242 & - \\
\hline ISO VG 320 & 320 & 288 & 352 & - \\
\hline ISO VG 460 & 460 & 414 & 506 & - \\
\hline ISO VG 680 & 680 & 612 & 748 & - \\
\hline ISO VG 1000 & 1000 & 900 & 1100 & - \\
\hline ISO VG 2200 & 2200 & 1980 & 2420 & - \\
\hline ISO VG 3200 & 3200 & 2880 & 3520 & - \\
\hline
\end{tabular}

https:/ / www.widman.biz/English/Tables/DIN-51519.html (accessed on 12 January 2021).

\section{Conclusions}

This study revealed the physicochemical properties and rheological behavior of EWCO and EWCOME at different shear rates and temperatures. The viscosity of epoxides increased as a result of chemical modifications that increased the intermolecular interactions among the molecules. The epoxides are considerably more polar and, as a result, had a significantly higher viscosity. The temperature effect was also studied for EWCO and EWCOME, revealing insignificant change in the viscosities with temperature. The power- 
law model was applied to model the rheological behavior, and the results show that both the epoxides lie in the Newtonian region as $n$ values are nearly equal to 1 . EWCO and EWCOME show a favorable viscosity index (164.94 and 151.97) for lubricant requirements, and they could complement up to ISO VG 10 (for EWCOME) and ISO VG 220 (for EWCO) lubricant standards.

Author Contributions: Conceptualization, A.K.P., V.B.B. and V.V.G.; methodology, A.K.P., V.B.B. and V.V.G.; validation, A.K.P., V.B.B. and V.V.G.; experiment, A.K.P., V.B.B.; formal analysis, A.K.P., investigation, A.K.P., V.B.B. and V.V.G.; writing-original draft preparation, A.K.P.; writing-review and editing, A.K.P., V.B.B. and V.V.G.; supervision, V.V.G. and V.B.B. All authors have read and agreed to the published version of the manuscript.

Funding: This research received no external funding.

Institutional Review Board Statement: Not applicable.

Informed Consent Statement: Not applicable.

Data Availability Statement: Not applicable.

Acknowledgments: We greatly acknowledge the FIST, DST, SR/FST/ETII-028/2010 for providing the facility of the Anton Paar Rheometer (MCR 301) in our chemical engineering department analytical laboratory, IIT Guwahati. We sincerely acknowledge the Centre of Excellence for Sustainable Polymers (CoE-SusPol) at IIT Guwahati, for providing the research facilities.

Conflicts of Interest: The authors declare that they have no conflict of interest.

\section{References}

1. Bart, J.C.J.; Gucciardi, E.; Cavallaro, S. Renewable lubricants. Biolubricants 2013, 1-9. [CrossRef]

2. Lea, C.W. European development of lubricants derived from renewable resources. Ind. Lubr. Tribol. 2002, 54, 268-274. [CrossRef]

3. Octave, S.; Thomas, D. Biorefinery: Toward an industrial metabolism. Biochimie 2009, 91, 659-664. [CrossRef]

4. Borugadda, V.B.; Somidi, A.K.R.; Dalai, A.K.; Borugadda, V.B.; Somidi, A.K.R.; Dalai, A.K. Chemical/Structural Modification of Canola Oil and Canola Biodiesel: Kinetic Studies and Biodegradability of the Alkoxides. Lubricants 2017, 5, 11. [CrossRef]

5. Rani, S.; Joy, M.L.; Nair, K.P. A comparative study of polymeric additives as biodegradable viscosity boosters for biolubricant formulations. Proc. Inst. Mech. Eng. Part J. J. Eng. Tribol. 2015, 229, 1079-1085. [CrossRef]

6. Hinman, M.; Rhee, I.S. Chapter 45 I Environmental Characteristics of Fuels and Lubricants. In Fuels and Lubricants Handbook: Technology, Properties, Performance, and Testing, 2nd ed.; Totten, G., Shah, R., Forester, D., Eds.; ASTM International: West Conshohocken, PA, USA, 2004; ISBN 978-0-8031-7090-2. [CrossRef]

7. Borugadda, V.B.; Goud, V.V. Improved thermo-oxidative stability of structurally modified waste cooking oil methyl esters for bio-lubricant application. J. Clean. Prod. 2016, 112, 4515-4524. [CrossRef]

8. India Industrial Lubricant Market by Lubricant Type (Metal Working Fluid, Industrial Engine Oil, Hydraulic Oil, Grease, Gear Oil and Others), By Application, By End Use, By Sales Channel, Competition, Forecast \& Opportunities, 2013-2023. 2019. Available online: https:/ / www.techsciresearch.com/report/india-industrial-lubricant-market/3750.html (accessed on 12 January 2021).

9. Carole, T.M.; Pellegrino, J.; Paster, M.D. Opportunities in the industrial biobased products industry. Appl. Biochem. Biotechnol. Part A Enzym. Eng. Biotechnol. 2004, 115, 871-885. [CrossRef]

10. Mohanty, A.K.; Misra, M.; Drzal, L.T. Sustainable Bio-Composites from renewable resources: Opportunities and challenges in the green materials world. J. Polym. Environ. 2002, 10, 19-26. [CrossRef]

11. Xu, Y.Q.; Qu, J.P. Mechanical and rheological properties of epoxidized soybean oil plasticized poly(lactic acid). J. Appl. Polym. Sci. 2009, 112, 3185-3191. [CrossRef]

12. McNutt, J.; He, Q.S. Development of biolubricants from vegetable oils via chemical modification. J. Ind. Eng. Chem. 2016, 36, 1-12. [CrossRef]

13. Khot, S.N. Development and application of triglyceride-based polymers and composites. J. Appl. Polym. Sci. 2001, 82, 703-723. [CrossRef]

14. Guo, A.; Demydov, D.; Zhang, W.; Petrović, Z.S. Structure and Properties of Halogenated and Non-halogenated Soy-Based Polyols. J. Polym. Environ. 2002, 10, 49-52. [CrossRef]

15. Berry, G.C.; Fox, T. The viscosity of polymers and their concentrated solutions. Fortschr. der Hochpolym. 2006, 261-357. [CrossRef]

16. García-Zapateiro, L.A.; Franco, J.M.; Valencia, C.; Delgado, M.A.; Gallegos, C. Viscous, thermal and tribological characterization of oleic and ricinoleic acids-derived estolides and their blends with vegetable oils. J. Ind. Eng. Chem. 2013, 19, 1289-1298. [CrossRef]

17. Campanella, A.; Rustoy, E.; Baldessari, A.; Baltanás, M.A. Lubricants from chemically modified vegetable oils. Bioresour. Technol. 2010, 101, 245-254. [CrossRef] 
18. Erhan, S.Z.; Perez, J.M. Biobased industrial fluids and lubricants. J. Am. Oil Chem. Soc. 2002, 136.

19. Wang, E.; Xiang Ma, X.; Tang, S.; Yan, R.; Wang, Y.; Riley, W.W.; Reaney, J.T.M. Synthesis and oxidative stability of trimethylolpropane fatty acid triester as a biolubricant base oil from waste cooking oil. Biomass Bioenergy 2014, 66, 371-378. [CrossRef]

20. Ciannamea, E.M.; Ruseckaite, R.A. Pressure sensitive adhesives based on epoxidized soybean oil: Correlation between curing conditions and rheological properties. J. Am. Oil Chem. Soc. 2018, 95, 4. [CrossRef]

21. Hernández-Sierra, M.T.; Bravo-Sánchez, M.G.; José, E.; Báez, J.E.; Luis, D.; Aguilera-Camacho, L.D.; García-Miranda, J.S.; Moreno, K.J. Improvement Effect of Green Lubricants on the Tribological and Mechanical Performance of 4140 Steel. Appl. Sci. 2019, 9, 4896. [CrossRef]

22. Libor, M. Rheology of epoxy networks near the gel point. Polym. Bull. 1991, 116, 109-116.

23. Sun, S.; Yang, G.; Bi, Y.; Liang, H. Lubricants from chemically modified vegetable oils. J. Am. Oil Chem. Soc. 2011, 88, 245-254. [CrossRef]

24. Frenkel, J. The Viscosity of Liquids. Nature 1930, 125, 581-582. [CrossRef]

25. Borugadda, V.B.; Goud, V.V. Synthesis of Waste Cooking Oil Epoxide as a Bio-Lubricant Base Stock: Characterization and Optimization Study. J. Bioprocess Eng. Biorefinery 2014, 3, 57-72. [CrossRef]

26. Enweremadu, C.C.; Mbarawa, M.M. Technical aspects of production and analysis of biodiesel from used cooking oil-A review. Renew. Sustain. Energy Rev. 2009, 13, 2205-2224. [CrossRef]

27. Dinda, S.; Patwardhan, A.V.; Goud, V.V.; Pradhan, N.C. Epoxidation of cottonseed oil by aqueous hydrogen peroxide catalysed by liquid inorganic acids. Bioresour. Technol. 2008, 99, 3737-3744. [CrossRef]

28. Borugadda, V.B.; Goud, V.V. Thermal, oxidative and low temperature properties of methyl esters prepared from oils of different fatty acids composition: A comparative study. Thermochim. Acta 2014, 577, 33-40. [CrossRef]

29. La Scala, J.; Wool, R.P. Rheology of chemically modified triglycerides. J. Appl. Polym. Sci. 2005, 95, 774-783. [CrossRef]

30. Wu, X.; Zhang, X.; Yang, S.; Chen, H.; Wang, D. The study of epoxidized rapeseed oil used as a potential biodegradable lubricant. J. Am. Oil Chem. Soc. 2000, 77, 561-563. [CrossRef]

31. Sharma, Y.C.; Singh, B.; Upadhyay, S.N. Advancements in development and characterization of biodiesel: A review. Fuel 2008, 87, 2355-2373. [CrossRef]

32. Adhvaryu, A.; Liu, Z.; Erhan, S.Z. Synthesis of novel alkoxylated triacylglycerols and their lubricant base oil properties. Ind. Crops Prod. 2005, 21, 13-119. [CrossRef]

33. Kleinová, A.; Fodran, P.; Brnčalová, L.; Cvengroš, J. Substituted esters of stearic acid as potential lubricants. Biomass Bioenergy 2008, 32, 366-371. [CrossRef]

34. Adhvaryu, A.; Erhan, S.Z. Epoxidized soybean oil as a potential source of high-temperature lubricants. Ind. Crop. Prod. 2002, 15, 247-254. [CrossRef]

35. Pang, B.; Wang, S.; Chen, W.; Hassan, M.; Lu, H. Effects of flow behavior index and consistency coefficient on hydrodynamics of power-law fluids and particles in fluidized beds. Powder Technol. 2020, 366, 249-260. [CrossRef]

36. Yen, H.Y.; Yang, M.H. The effect of metal ions additives on the rheological behavior of polyacrylamide solution. Polym. Test. 2003, 22, 389-393. [CrossRef]

37. Gorla, G.; Kour, S.M.; Padmaja, K.V.; Karuna, M.S.L.; Prasad, R.B.N. Preparation and properties of lubricant base stocks from epoxidized karanja oil and its alkyl esters. Ind. Eng. Chem. Res. 2013, 52, 16598-16605. [CrossRef]

38. Hwang, H.; Erhan, S.Z. Synthetic lubricant basestocks from epoxidized soybean oil and Guerbet alcohols. Ind. Crop. Prod. 2006, 23, 311-317. [CrossRef] 